Chris Evans \& Göran Rydén, Baltic iron in the Atlantic world in the eighteenth century

Leyde/Boston, Brill, 2007.

\title{
Denis Woronoff
}

\section{(2) OpenEdition \\ Journals}

Édition électronique

URL : http://journals.openedition.org/dht/1065

DOI : 10.4000/dht.1065

ISSN : $1775-4194$

\section{Éditeur :}

Centre d'histoire des techniques et de l'environnement du Cnam (CDHTE-Cnam), Société des élèves du CDHTE-Cnam

\section{Édition imprimée}

Date de publication : 1 juin 2008

Pagination : 222-224

ISBN : 978-2-95-30779-1-9

ISSN : 0417-8726

Référence électronique

Denis Woronoff, "Chris Evans \& Göran Rydén, Baltic iron in the Atlantic world in the eighteenth century », Documents pour I'histoire des techniques [En ligne], 15 | 7 er semestre 2008, mis en ligne le 22 octobre 2010, consulté le 24 septembre 2020. URL : http://journals.openedition.org/dht/1065 ; DOI : https:// doi.org/10.4000/dht.1065

Ce document a été généré automatiquement le 24 septembre 2020

(c) Tous droits réservés 


\section{Chris Evans \& Göran Rydén, Baltic iron in the Atlantic world in the eighteenth century}

Leyde/Boston, Brill, 2007.

\section{Denis Woronoff}

\section{RÉFÉRENCE}

Chris Evans \& Göran Rydén, Baltic iron in the Atlantic world in the eighteenth century, Leyde/Boston, Brill, 2007.

1 Voici l'œuvre commune de deux historiens, un Britannique et un Suédois, déjà connus pour des travaux sur leurs sidérurgies nationales. L'alliance ici a un sens fort. Il s'agit de donner à comprendre le lien qui a uni au XVIII siècle fer suédois et quincaillerie anglaise, à l'intérieur d'un système d'échanges beaucoup plus large et passablement sophistiqué. Tout commence en Baltique. On savait déjà que cette Méditerranée nordique fournissait le goudron pour l'étanchéité, le chanvre pour les voiles et les beaux mâts de sapin nécessaires aux marines du reste de l'Europe. Sans les pays baltes, les vaisseaux des Provinces-Unies, de la Grande-Bretagne et du Royaume de France n'auraient pu bénéficier des qualités requises. À ces fournitures stratégiques - on n'oubliera pas au passage l'importance des grains - la Suède ajoute au XVII ${ }^{\mathrm{e}}$ siècle des envois croissants de son excellent fer de Dannemora (dans la région d'Uppsala). L'Angleterre devient alors la principale cliente de ces barres de fer. Son économie se développe à vive allure et les arrivages du Pays Basque espagnol qui avaient répondu aux premiers besoins de la nouvelle puissance ne suffisent plus, désormais. Nos auteurs montrent que les marchands de Londres prennent alors les commandes de ce nouveau trafic. Ils n'expliquent guère, en revanche, comment ceux-ci cèdent leur place, au premier tiers du XVIII siècle, à leurs concurrents de Bristol, au sud-ouest de l'Angleterre, à faible distance de la mer. Ils rappellent cependant que cette ville était 
alors un grand port colonial, soucieux de compenser par des exportations de marchandises et d'esclaves les tonnages considérables de sucre qui lui venaient d'outre-mer. Voilà donc le premier segment établi.

Le district de Dannemora produit des fers de qualité remarquables ou au moins honnête. Cette sidérurgie exportatrice - la faiblesse du marché intérieur n'autorise pas d'autres issues - a été installée dans les années 1620 par des techniciens wallons; elle vit encore de capitaux hollandais. Les descendants du héros de cette aventure industrielle, Louis De Geer, continuent de contrôler au XVIII ${ }^{e}$ siècle les principales usines. Bristol accueille ces fers que l'Angleterre ne saurait produire, faute de disposer d'un minerai de qualité équivalente et de forêts assez étendues pour répondre aux besoins en charbon de bois. La sidérurgie britannique doit fournir à l'économie domestique et au commerce international toutes sortes d'outils (au premier rang desquels les limes) et d'instruments (rasoirs, lancettes etc.) dont le tranchant est nécessairement en acier. Le pôle allemand (Ruhr) et le pôle autrichien (Styrie, Carinthie) gardent au XVIII siècle leur réputation d'excellence mais la montée en puissance de la métallurgie de l'acier dans les Iles britanniques les affaiblit. Le meilleur fer suédois, "l'orground », est progressivement monopolisé par les négociants anglais installés en Suède. De Bristol, il est envoyé dans de petites aciéries puis transformé dans les Midlands et le Sud du Pays de Galles dans les multiples déclinaisons de la quincaillerie. Evans et Rydén font ici la synthèse de la littérature du sujet, évoquant en particulier le rôle de Birmingham. Leur mérite est de replacer ce capital de connaissances dans une dynamique des flux qui échappe au découpage conventionnel et statique des histoires nationales.

3 Une partie de ce matériel associé à un fer plus commun (dit "d'esclaves») et à des pièces de textile vogue vers l'Afrique (golfe de Biafra) pour compenser, selon le principe du commerce triangulaire, les cargaisons d'esclaves envoyés aux Amériques. $\mathrm{Au}$ retour les marchands de Bristol soldent leurs échanges avec la Baltique en y envoyant, entre autres, les produits coloniaux que réclament ses riverains. Ce circuit implique des départs échelonnés qui tiennent compte de la chronologie décalée de la navigation en mer (glaces de la Baltique), de la saison des rafles d'esclaves et du temps des récoltes dans le Nouveau Monde. La démonstration est neuve et brillante. La boucle ainsi dessinée est loin de suffire à décrire la complexité du modèle. Du côté de la Baltique, la Russie devient grosse exportatrice de fers, vers 1725, grâce à l'essor de la sidérurgie de l'Oural. Ces fers sont moins réputés que ceux du Bergslagen suédois. Ils sont généralement employés à la fabrication des clous. Leur principal avantage est d'être peu chers. Le négoce anglais s'empare de cette nouvelle filière qui permet de combler les demandes massives de Birmingham ou de Sheffield, au moment où la production suédoise semble plafonner.

4 À l'étape américaine du voyage, autres changements. Une sidérurgie à la production significative est née au XVIII siècle dans les colonies britanniques. Vers 1750 , l'effectif des usines se monte à 28 hauts-fourneaux et à 46 forges. Est-ce une chance de se délivrer de la dépendance de la Métropole à l'égard de la Suède ? En fait, passé la miXVIII ${ }^{e}$ siècle, le potentiel américain parait de plus en plus destiné à la consommation fébrile du marché intérieur. Par une ironie de l'histoire, c'est aux États-Unis que les fers de Suède trouveront, à partir de 1820, un débouché appréciable. Evans et Rydén introduisent dans cette saga du négoce international l'histoire propre des techniques sidérurgiques. En effet, la disette de charbon de bois en Grande-Bretagne peut être 
conjurée par le changement de combustible. La houille cokéifiée pour le haut-fourneau change complètement la donne. Abraham Derby en a fait la démonstration en 1709. Estce assuré pour autant ? À la suite d'autres historiens, nos auteurs font apparaitre que la fonte au coke introduite dans des forges marchant au bois est plus difficile à affiner que la fonte traditionnelle. Le coût final, dans un système qui n'a pas achevé sa mutation, n'est pas forcément à l'avantage du combustible fossile. La transformation essentielle viendra donc dans les années 1780-1800, lorsque, grâce à Henry Cort, le puddlage à la houille et le laminoir commenceront à remplacer l'affinerie et le marteau. Alors, les fers suédois et russes ne seront plus nécessaires à «l'atelier du monde ». Une trentaine d'années seront nécessaires pour que la sidérurgie britannique devienne autosuffisante. Mais le déclin du « Baltic iron » a déjà commencé.

5 Ce travail se réclame à bon droit de Fernand Braudel et d'Immanuel Wallerstein. On n'aura garde d'écraser Evans et Rydén sous la comparaison. Pourtant, le concept d'économie-monde et l'étude synthétique de la Méditerranée nordique y font inévitablement penser. D'ailleurs, sous l'impulsion des deux auteurs qui sont sur le front depuis longtemps, des historiens russes, scandinaves et britanniques ont déjà travaillé dans ce sens. Il faudrait, pour améliorer encore le modèle, que ces chercheurs soient plus attentifs aux autres régions sidérurgiques de l'Europe du XVIII ${ }^{\mathrm{e}}$ siècle, à commencer par la France. Le lecteur est surpris que, sur la foi de Réaumur, il soit dit que le Royaume dédaignait le fer de Suède. En 1789, au moins 15 \% des exportations sidérurgiques du Bergslagen sont destinés à la France qui achète aussi une part non négligeable des exportations des fers de l'Oural. C'est un autre cercle à combiner à ceux, nés dans la Baltique, qui sont décrits ici avec précision et talent.

\section{AUTEURS}

\section{DENIS WORONOFF}

Université Paris-I 